\title{
Genetic Algorithm Applied to Planning IEEE 802.11g Networks
}

\author{
Hamid Barkouk, El Mokhtar En-Naimi, Aziz Mahboub
}

\begin{abstract}
The problem of planning local wireless network IEEE $802.11 \mathrm{~g}$ consists of automatically positioning and setting up wireless access points (APs) in order to provide access to the local network with the desired coverage and the required quality of service (QOS).In addition to the complexity of predicting the Quality of Service (QoS) of a network from the variables of the problem (positions, parameters and frequency of the APs), the planning of WLAN networks faces several difficulties. In particular, the location of APs and the allocation of frequencies. There is no single model to solve the problem of designing wireless local networks. Depending on the situations and the hypotheses studied, different criteria can be considered and expressed in terms of constraints to be observed or in terms of objectives to be optimized. The first distinction is to separate the financial criteria from the network quality criteria. The nature of these two criteria being fundamentally different. Then there are a variety of service quality criteria, but we can still group them into three main categories: coverage criteria, interference criteria and capacity criteria.. In this article, we will use an optimization method based on an algorithm of stochastic optimization, which is also based on the mechanisms of natural selection and of genetic. It is genetic algorithm. Our goal consist of minimizing the total interaction between the APs to perform the good choices when deploying a network $802.11 \mathrm{~g}$ in a way that gives users signal-to-interference ratios (SIR) greater than the required threshold B.
\end{abstract}

Keywords: Access point, optimization, genetic algorithm, frequency assignment, power management, load balancing, and signal-to-interference ratio

\section{INTRODUCTION}

W LANs don't consist a new concept, they have existed since 1997. In the beginning, the 802.11 networks offer an internet speed lower than $1 \mathrm{Mbps}$. The adoption of 802.11b in 1999 pushed the limit to11 Mbps, it made it in a competition with wired Ethernet that offers $10 \mathrm{Mbps}$ [1]. However, 802.11a and 802.11g offer an internet speed that can reach a 54 Mbps [2], a threat for Fast wired Ethernet.

Manuscript received on March 24, 2021.

Revised Manuscript received on March 30, 2021.

Manuscript published on April 30, 2021.

* Correspondence Author

Hamid Barkouk*, Faculty, Sciences and Technologies, Tangier, Morocco at the University of Abdelmalek Essaadi.

El Mokhtar En-Naimi, Faculty, Department of Computer Sciences of Sciences and Technologies of Tangier,

Aziz Mahboub, Faculty, Department of Computer Sciences, of Sciences and Technologies of Tangier,

(C) The Authors. Published by Blue Eyes Intelligence Engineering and Sciences Publication (BEIESP). This is an open access article under the CC BY-NC-ND license (http://creativecommons.org/licenses/by-nc-nd/4.0/)
Even though wireless networks under the norm of 802.11 have a LAN topology, technicians will have to face a new problem of planning and optimization whose variables are the set of possible configurations of access points (APs) (frequency, power and load balancing) [3]. The first problem that was encountered and dealt with is the assignment of frequency which means the attribution of frequencies of all APs while minimizing interference between them, as well as providing users with signal-to-interference ratios (SIR) higher than the required threshold $\beta$ [4]. This planning problem is formulated within the framework of integer linear programming (ILP) [5]. In this research, We have extended the work presented of (Haidar 2008 and Boulmalf 2009) [6][7] proposing a stochastic optimization method which assigns channels to the AP based on minimizing total interference between APs, while maintaining the SIR superior a certain threshold $\beta$. This article is organized as follows; we're discussing the interferences of channels in IEEE 802.11 in chapter 2 and 3 . Then, we will present the attribution model of frequencies. Our optimization method is discussed in section 4. In section 5, we will present the problem of optimization and its mathematical formula, we will analyze and discuss the results obtained on a proposed scenario in section 6 . Finally, in section 7 , we will shortly present our future work.

\section{INTERFERENCES IN IEEE 802.11}

The research lead by (Henty 2001) [8] have shown that the speed changes when access points or the users are located near a transmitter, which causes interferences (problems of site planning). Data rate may also be limited due to a number of specific factors, especially: the distance between WLAN adapters: APs and network interference cards (NIC), transmission power level and waveguide effect [9]. Therefore, even if the new available products $802.11 \mathrm{~g}$ are able to assure a signal rate of $54 \mathrm{Mbps}$, in practice, the actual speed is more likely to be much lower (in the range of 10 to 12 Mbps). In the results given by (Boulmalf 2008) [7] we see that the interference of Co-channel causes a weakening in TCP throughput in the order of 9Mbps to $2 \mathrm{Mbps}$ and UDP from 9.7 Mbps to 8.6 Mbps.

\section{CHANNEL OVERLAPPING IN IEEE 802.11G}

In IEEE 802.11g standard there are 13 channels [10]. As illustrated in figure 1, channels 1, 6 and 11 do not interfere, nevertheless,

Published By:

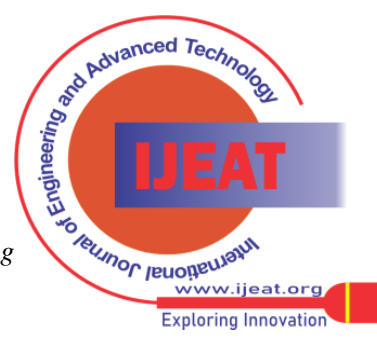

Blue Eyes Intelligence Engineering \& Sciences Publication (C) Copyright: All Rights Reserved 
channel 1 which has a band of 2,402 GHz à 2,424 GHz crosses from channel 2 to 5 . Each channel has a bandwidth of $22 \mathrm{MHz}$. If this bandwidth is used with other access points, an overlap of frequencies then creates disturbances [11][12].

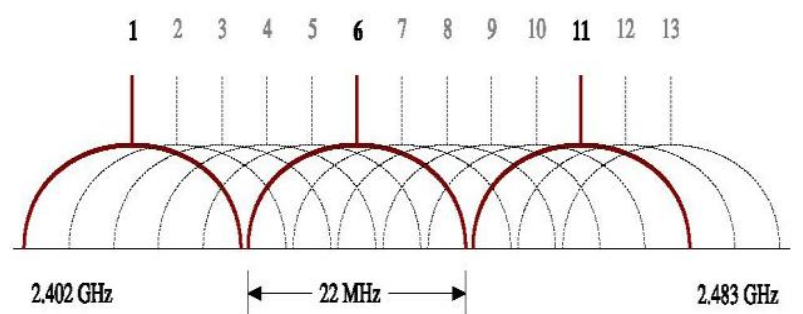

Fig. 1. channels in IEEE 802.11g

The center of two frequencies of two adjacent channels is only separated by a distance of $5 \mathrm{MHz}$. The interference coefficient is given by the following formula:

$\alpha=\operatorname{Max}\left(0,1-\frac{\left|C_{j}-C_{k}\right|}{n}\right)$

If $\mathrm{Cj}$ where the channel is attributed at $\mathrm{AP}_{\mathrm{J}}, \mathrm{C}_{\mathrm{k}}$ is the affected channel at $\mathrm{AP}_{\mathrm{k}}, \mathrm{n}$ is the non-accumulation of the two parts of the adjacent channels and is equal to 5.The propagation model used in our study is as follows, (Julian 2002):

$P^{r}=P K\left(\frac{d_{0}}{d}\right)^{\gamma}$

Where $\mathbf{P r}$ is the received power, $\mathbf{P}$ is the transmitted power, $\mathbf{d}$ is the distance between the transmitter and receiver, $\mathbf{d o}$ is the reference distance for far-field antennas, often taken to ensure that the normalization constant $\mathrm{K}\left(\mathrm{d}_{0}\right)^{\gamma}$ is equal to 1 . On the other hand the exponent of path loss $\gamma$ is generally between 2 and 6 , for the majority of interior and exterior environments. Model (2) was modified by (Aouam 2009) [22] so that it takes into consideration the interference coefficient $a$.

Such as : $\quad \gamma=2+\left(5-\alpha_{j k}\right)=7-\alpha_{j k}$

$$
P_{j k}^{r}=P_{k}^{j k} d^{-\gamma}
$$

And $\quad \alpha_{j k}=5 * \max \left(0,1-\left|\frac{C_{j}-C_{k}}{5}\right|\right)$

$\alpha_{j k}$ is the interference degree between two APs: $j$ and $k$. so $\alpha_{j k} \in\{0,1,2,3,4,5\}, 0$ means no interference and 5 refers to the bigger interference degree. If two APs use the same channel (co_channel) $\mathrm{C}_{\mathrm{j}}$ equal $\mathrm{C}_{\mathrm{k}}, \alpha_{j k}=5$.

\section{FREQUENCY ASSIGNMENT PROBLEM}

The problem of channel assignment that we are going to study consists of choosing an optimal assignment of APs frequencies in a way that the total interference between the APs is reduced to a minimum, while ensuring that for each user, SIR should be greater than a preselected threshold which reflects good quality of service in the network.

The problem of optimal assignment of channels can be settled in the following mathematical formula:

$$
\operatorname{Minimize}\left\{I_{1}(C)\right\}=\sum_{j=1}^{N A P} \sum_{k \neq j}^{N A P} I_{j k}\left(P_{j k}\right)
$$

Such as:

$$
\mathrm{C}=\left\{\mathrm{C}_{1}, \mathrm{C}_{2}\right.
$$

$\mathrm{k}$ is the set of Aps

$$
I_{j k}=P_{j k} \times d_{j k}^{-2-(5-\alpha(C j, C k))}
$$

Under the inequality constraint:

$$
\operatorname{SIR}_{i j} \leq \boldsymbol{\beta}
$$

With:

$$
\begin{gathered}
S I R_{i j}(C)=\frac{P j d_{i j}^{-2}}{\sum_{k \neq j} P_{k} d_{i k}^{-\left(7-\alpha_{j k}\right)} W_{j k \alpha}+\eta_{i}} \\
P_{j} d_{i j}^{-2} \geq \beta \cdot\left\{\left[\sum_{j \neq k} P_{k} d_{i k}^{-\left(5-\alpha_{j k}\right)} W_{j k \alpha}\right]+\eta_{i}\right\}
\end{gathered}
$$

\section{Such as :}

I : objective function of total interference.

$\mathrm{I}_{\mathrm{jk}}$ : interference between $\mathrm{AP}_{\mathrm{j}}$ and $\mathrm{AP}_{\mathrm{k}}$

$\mathrm{P}_{\mathrm{JK}}$ : power transmitted by $\mathrm{AP}_{\mathrm{k}}$.

$\mathrm{d}_{\mathrm{jk}}$ : distance between $\mathrm{AP}_{\mathrm{j}}$ and $\mathrm{AP}_{\mathrm{k}}$

NAP : number of access points to be installed

$\alpha$ : interference coefficient between $\mathrm{AP}_{\mathrm{j}}$ and $\mathrm{AP}_{\mathrm{k}}$

$$
\text { Such as : } \alpha=5^{*} \max \left(0,1-\frac{|C j-C k|}{5}\right)
$$

$\mathrm{C}$ : set of $\mathrm{Cj}$ channels such as:

$$
\mathrm{j}=\{1,2,3, \ldots \ldots, \mathrm{NAP}\}
$$

$\mathrm{Cj}$ : assigned channel to APj

$\beta$ : The minimal threshold of SIR required

The inequalities (5) assure that, for each user i, the SIR either greater than at the constant $\beta$.

$\mathrm{j}$ in equation (5) refers to the AP and the $\mathrm{i}$ to the user who is connected to the APj..

\section{GENETIC ALGORITHMS}

\section{A. Principle of the genetic algorithms}

Genetic algorithms are stochastic optimization methods defined by J. HOLLAND and his colleagues in

1975 [15]. Theyjlare based on natural and biological process: The evolution of living species. This evolves thanks to two mechanisms: natural selection and reproduction. Genetic algorithms search for the extremum or the extrema of a function defined by a given space [13][14]. To use them, we must have the following five elements:

- A basis of population element coding. This step associates to each point in the state space a data structure.

- A mechanism for generating the initial population. This mechanism should be able to produce a population of inhomogenous individuals that serve as a base for future generations. will 
- The choice of the people is important because it makes the convergence towards the global optimum more or less rapid.

- A function to be optimized, called fitness function or individual evaluation function.

- Operators making it possible to diversify the population over the generations and to explore the research space.

- Sizing parameters: people's number, total number of generations, probabilities of application of genetic operators.

Each individual presents a point in the set of research space to which we associate the value of the criterion to be optimized [16]. We generate a population of individuals randomly for which the genetic algorithm attempts to select the best individuals while ensuring an efficient exploration of the research space. After the random selection of the two parents P1 and P2, we randomly apply the crossover operator with a probability Pc that generates two children C1 and C2 (Fig.1). We then modify certain genes of $\mathrm{C} 1$ and $\mathrm{C} 2$ by applying the mutation operator $\mathrm{Pm}$, which produces two new individuals C1' and C2 ' (Fig.2) for which we assess the level of adaptation before inserting them into the new population. Unlike reproduction and crossbreeding promotes intensification, the mutation operator promotes the diversification of individuals [17]. We reiterates the selection, crossover and mutation operators in order to complete a new population, this completes the process of developing a generation. We redo again the previous operations till a stop criterion is met.

\section{Crossover}

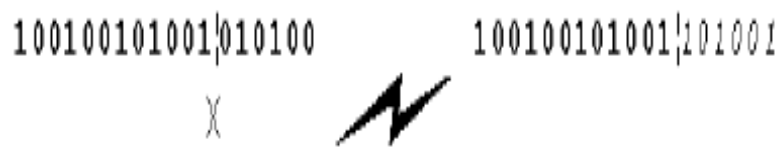

\section{$001000101010101001 \quad 001000101010,010100$}

\section{Mutation}

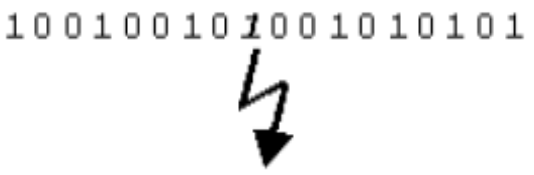

100100100001010101

\section{Fig. 2.Crossover and mutation operations}

\section{B. Organizational Chart of Genetic Algorithms}

This organization chart explains all the steps to resolve the problem of frequency assignment. The Genetic Algorithm starts off with an initial population and it is followed by Selection, Crossover and Mutation processes.

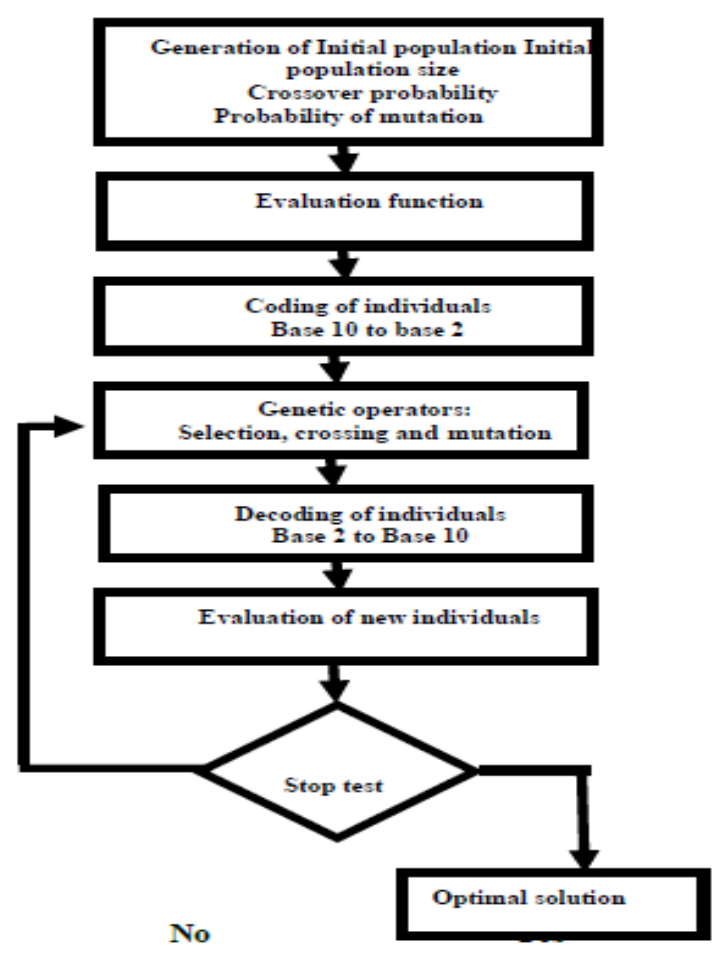

Fig. 3.Steps followed to resolve the FAP

\section{Penalty Function}

We will use the penalty method [20] to transform the original constrained problem into an unconstrained auxiliary problem where the minimum is the same in both cases [21]. The basic principle consists of modifying the criterion by adding a penalization function while using method 4 proposed by [Michalewicz and Attia 1994]

The new objective function is as follows:

$$
\operatorname{eval}(C, R)=I_{1}(C)+\frac{1}{R} \times \sum_{j} f_{j}{ }^{2}(C)
$$

With:

$\mathrm{R}=$ Penalty coefficient fixed at a constant value 0.2

$$
f_{i}(C)=\max \left(0, g_{i}(C)\right)
$$

With :

$$
g_{j}(C)=\operatorname{SIR}_{i j}(C)-\beta \leq 0
$$

\section{Coding Individuals}

In our work we used binary coding. We code the variables $\mathrm{Cj}$ with binary strings of 4 bits as follows:

The string 0001 code $\min \mathrm{Cj}=1$

The string 1101 code max $\mathrm{Cj}=13$

The transformation of a binary string to an integer can be executed as follows:

$\mathrm{Cj}=\sum_{i=1}^{4} a_{i} 2^{4-i}$

With:

$\alpha \mathrm{i}=$ the bit at position $\mathrm{i}$

E. Algorithm

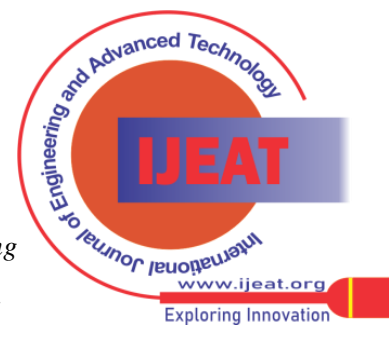


Based on the diagram above related to genetic algorithm, we propose an algorithmic approach to solve this optimization problem.

Step 1: initialization

A uniform distribution of a number of users and an initial configuration of APs with power $100 \mathrm{~mW}$ and random frequency assignment

Step 2: frequency assignment

Attribution of $\mathrm{C}$ Frequencies to the set of APs while minimizing interference.

Step3: power management

Supposing that the assignment of frequencies is optimal, the problem of power management (PMP) will be managed by assigning different power levels to the APs.

\section{ILLUSTRATION}

\section{$>$ Scenario $\mathrm{N}^{\circ} 1$}

Let us consider the802.11g network with 3APs as shown in the figure bellow:

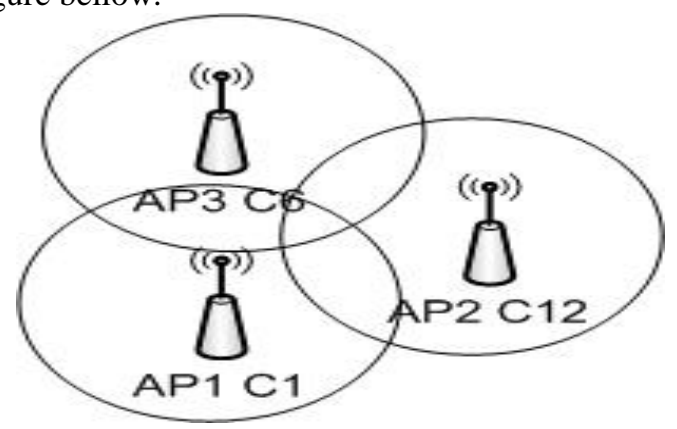

Fig. 4.Scenario1: Network with 3 APs

We can see that the method GA chose the optimal solution (C1, C12, C6) with a total of interferences between the 3 APs which is zero.

\section{$>$ Scenario $\mathrm{N}^{\circ} 2$}

We consider the 802.11g network, made of 8 Aps and we limit the set of channels on the three optimal channels (C1, C6, C11).

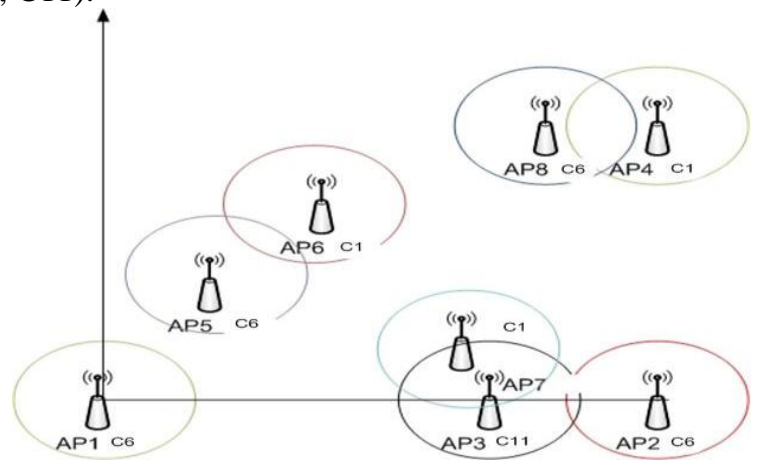

Fig. 5.Scenario2: Network with 8 APs

In the table below, we present the results of GA compared with (Aouam 2009) [22].

Table- I: Scenario2 results of GA compared with

(Aouam 2009)

\begin{tabular}{|l|l|l|}
\hline $\begin{array}{l}\text { AP coordinates }(x, y) \\
\mathrm{x} \text { and } y \text { are in meters }\end{array}$ & $\begin{array}{l}\text { Channel } \\
(\text { Aouam 2009) }\end{array}$ & Channel \\
\hline$A P 1(0,0)$ & $C 6$ & $C 6$ \\
\hline$A P 2(100,0)$ & $C 6$ & $C 6$ \\
\hline$A P 3(70,0)$ & $C 1$ & $C 11$ \\
\hline$A P 4(100,70)$ & $C 1$ & $C 1$ \\
\hline$A P 5(20,30)$ & $C 11$ & $C 6$ \\
\hline
\end{tabular}

The assignment of optimal frequency found does not include the interference between the channels. In addition, the verage SIR is equal to $38 \mathrm{~dB}$ with total interferences between APs equal to $-24,81 \mathrm{dBm}$ which reflects a very good quality of service, in average. All the users have a SIR higher than $10 \mathrm{~dB}$.

\section{$>$ Scenario $\mathbf{N}^{\circ} 3$}

We consider the $802.11 \mathrm{~g}$ network with 80 users and 8 APs with the set of channels from 1 to 13 .

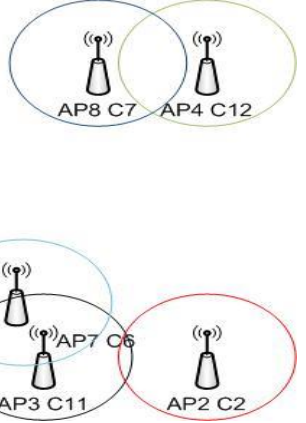

Fig. 6.Scenario 3: Network with 8 APs and 80 users

The power transmitted by each PA was fixed at $20 \mathrm{dBm}(100$ $\mathrm{mW})$. The threshold $\beta$ is fixed at $10 \mathrm{~dB}$.

The control of the parameters of the genetic algorithm is defined as follows: The initial population is composed of 30 individuals, the probabilities of crossover and mutation are respectively 0.6 and 0.01 . Generation number is 300.In the table below, we present the results of AG compared with (Aouam 2009) in case of scenario 3.

Table- 2 :Scenario3 results of GA compared with (aouam 2009)

\begin{tabular}{|l|l|l|}
\hline $\begin{array}{l}\text { AP coordinates }(x, y) \\
x \text { and } y \text { are in meters }\end{array}$ & $\begin{array}{l}\text { Channel } \\
(\text { Aouam 2009) }\end{array}$ & Channel \\
\hline AP1 $(0,0)$ & C6 & C4 \\
\hline AP2 $(100,0)$ & C6 & C2 \\
\hline AP3(70,0) & C1 & C11 \\
\hline AP4(100,70) & C1 & C12 \\
\hline AP5 $(20,30)$ & C11 & C8 \\
\hline AP6(40,50) & C6 & C3 \\
\hline AP7 $(65,15)$ & C1 & C6 \\
\hline AP8(80,70) & C11 & C7 \\
\hline SIR(DB) & 10 & 8.5 \\
\hline
\end{tabular}

Optimal frequencies assignment found does not include interferences between channels. In addition, the average SIR is equal to $38 \mathrm{~dB}$ with total interferences between APs equal to $-24.81 \mathrm{dBm}$ which reflects a very good quality of service, in average all the users have a SIR higher than $8.5 \mathrm{~dB}$. The results obtained show the efficiency of genetic algorithm and the method which allowed us to use all the available channels from 1 to 13 unlike (Aouam 2009), more than that AP3 and AP4 are close to each other (table 1), so we can't have the same channels (Aouam 2009). This proves the effectiveness of the method used.

\section{$>$ Scenario $\mathrm{N}^{\circ} 4$}

We consider 802.11g network with 80 users and 9 APs as shown in the figure below:

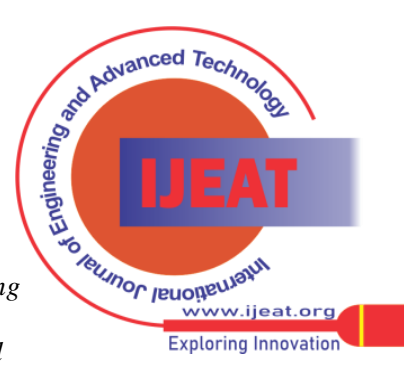




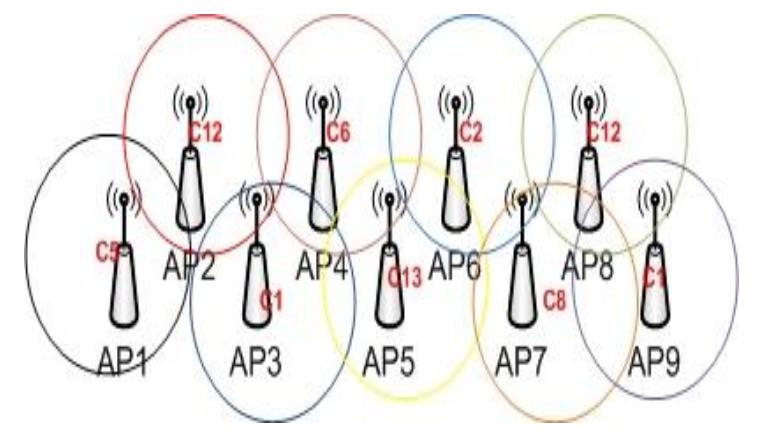

Fig. 7.Scenario 4: Network with 9 APs and 80 users

In the table below, we present the results of AG compared with (Aouam 2009) in case of scenario 4.

Table 3: Scenario4 results of GA compared with (aouam 2009)

\begin{tabular}{|l|c|c|}
\hline $\begin{array}{l}\text { AP coordinates }(x, y) \\
x \text { and } y \text { are in meters }\end{array}$ & $\begin{array}{l}\text { Channel } \\
\text { (Aouam 2009) }\end{array}$ & Channel \\
\hline AP1 $(\mathbf{0}, 0)$ & C6 & C5 \\
\hline AP2 $(10,10)$ & C1 & C12 \\
\hline AP3 $(20,0)$ & C11 & C1 \\
\hline AP4 $(30,10)$ & C6 & C6 \\
\hline AP5 $(40,0)$ & C1 & C13 \\
\hline AP 6 (50, 10) & C11 & C2 \\
\hline AP7 $(60,0)$ & C6 & C8 \\
\hline AP8 $(70,10)$ & C1 & C12 \\
\hline AP9(80, 0) & C11 & C1 \\
\hline
\end{tabular}

Table 3 show that the optimal frequency assignment found does not include the interference between the channels. In addition, the average SIR is equal to $35 \mathrm{~dB}$ with a total interference between the APs equal to $-26,36 \mathrm{dBm}$ which reflects a very good quality of service.

\section{POWER MANAGEMENT PROBLEM}

Supposing that the attribution of frequencies is optimal, the problem of power management (PMP) is managed by assigning five different power levels to APs, while reducing total network interference and ensuring that the required quality of service is achieved. In our case, we suggest five power levels in $(\mathrm{mW})$ Power $=\{100,50,25,12.5,6.25\}$.

\section{MATHEMATICAL FORMULA:}

$$
\mathrm{I}(P)=\sum_{j}\left[\sum_{k \neq j} P_{k}\left(d_{j k}\right)^{-\left(7-\alpha_{j k}\right)}\right] \text { (6) }
$$

Such as:

I : total interference

$\mathrm{P}$ : set of assigned powers :

$$
\text { APs }\{\mathrm{P} 1, \mathrm{P} 2, \ldots \ldots \ldots \ldots . \mathrm{P} k\}
$$

$\mathrm{k}$ : number of access points.

The problem of power management (PMP) can be laid in the following form:

$$
\operatorname{Minimize}\{I(P)\}
$$

With the constraint:

$$
\mathrm{I}(P)=\mathrm{I}_{1}(C)
$$

Method proposed by [Michalewicz and Attia 1994].

With : 0.2

$$
f_{i}(P)=\max \left(0, g_{i}(P)\right)
$$

With

$g_{j}(P)=I(P)-I_{1} \leq 0$

\section{$>$ Scenario $\mathrm{N}^{\circ} 5$}

In this scenario we have fixed the frequencies found in scenario 3 with the same number of users.

The table below shows the results

Table 4: Scenario5 results

\begin{tabular}{|l|c|c|}
\hline $\begin{array}{l}\text { AP coordinates }(x, y) \\
x \text { and } y \text { are in meters }\end{array}$ & Chanel & Power $(\mathbf{m W})$ \\
\hline AP1 $(0,0)$ & C5 & 100 \\
\hline AP2 $(10,10)$ & C12 & 25 \\
\hline AP3 $(20,0)$ & C1 & 100 \\
\hline AP4 $(30,10)$ & C6 & 100 \\
\hline AP5 $(40,0)$ & C13 & 6.25 \\
\hline AP 6 $(50,10)$ & C2 & 100 \\
\hline AP7 $(60,0)$ & C8 & 25 \\
\hline AP8 $(70,10)$ & C12 & 100 \\
\hline AP9 $(80,0)$ & C1 & 6.25 \\
\hline
\end{tabular}

Optimal power management reduced the total interference between APs. In addition, the average SIR is equal to $38 \mathrm{~dB}$ with a total of interferences between the APs that is equal to $-23.81 \mathrm{dBm}$ which always reflects a very good quality of service. In average, all users have a SIR that is higher than 8.5 $\mathrm{dB}$. The results obtained show the efficiency of genetic algorithm and the suggested method which allowed us to save almost $50 \%$ of power.

\section{CONCLUSION}

Resolving problems of optimization require strong, efficient and flexible methods. In order to overcome the complexity of the IEEE 802.11g wireless network planning problem, the results obtained in this work are promising and show the efficiency of the genetic algorithm , on the other hand this method has allows us to use all channels available from 1 to 13 and also save $50 \%$ of energy.

The study will not be completed until the resolution of two other issues related to the IEEE 802.11g wireless network planning: 
The power management problem (PMP) and the problem of balancing of load (LBP). This issues will be handled during next works.

\section{REFRENCES:}

1. Osama S, Aboul-Magd, "IEEE Standard 802.11 Overview", chapter part of book "Wireless Local Area Networks Quality of Service: An Engineering Perspective”, Wiley-IEEE Standards Association, 2008.

2. RAJU SHARMA, GURPAL SINGH, RAHUL AGNIHOTRI, "Comparison of performance analysis of 802.11a, 802.11b and 802.11g standard", (IJCSE) International Journal on Computer Science and Engineering, Vol. 02, No. 06, 2010, pp. 2042-2046.

3. Iana Siomina, Di Yuan, "Optimization of Channel Assignment and Access Point Transmit Power for Minimizing Contention in Wireless LANs", 5th International Symposium on Modeling and Optimization in Mobile, Ad Hoc and Wireless Networks and Workshops, Limassol, Cyprus, 16-20 April 2007.

4. Babul P. Tewari, Sasthi C. Ghosh,"Interference aware frequency assignment and association control for uplink and downlink traffic in WLAN", International Journal of Communication Networks and Distributed Systems, 29 May 2019, Volume 23, Issue 2.

5. P. Marwedel, "Integer Linear Programming”, Embedded System Design, Springer International Publishing AG 2018, pp 379-423.

6. Haidar, M., Ghimire, R., Al-Rizzo, M., Akl, R., Chan, Y. (2008) 'Channel Assignment in an IEEE 802.11 WLAN Based on Signal-to-interference Ratio', IEEE CCECE - Canadian Conference on Electrical and Computer Engineering: Communications and Networking,May.

7. Boulmalf, M., Aouam, T., and Harroud, H. (2008) 'Dynamic Channel Assignment in IEEE 802.11g', IEEE IWCMC 2009 Conference, Crete Greece, August.

8. Henty, B. E. (2001) 'Throughput Measurements and Empirical Prediction Models for IEEE 802.11b Wireless LAN (WLAN) Installations', Master thesis, Virginia Polytechnic Institute and State University, USA, August.

9. Amina Šljivo, Dwight Kerkhove, Le Tian, Jeroen Famaey, Adrian Munteanu, Ingrid Moerman, Jeroen Hoebeke, Eli De Poorter ," Performance Evaluation of IEEE 802.11ah Networks With High-Throughput Bidirectional Traffic", Sensors Journal, 23 January 2018.

10. Peter Miklavčič, "On the number of non-overlapping channels in the IEEE 802.11 WLANs operating in the $2.4 \mathrm{GHz}$ band", ELEKTROTEHNISKI VESTNIK ` 81(3): 148-152, January 2014.

11. Sandra Sendra, Miguel Garcia, Carlos Turro, Jaime Lloret ," WLAN IEEE $802.11 \mathrm{a} / \mathrm{b} / \mathrm{g} / \mathrm{n}$ indoor coverage and interference performance study", International Journal on Advances in Networks and Services, vol 4 no 1 \& 2, 2011.

12. Roni Shigueta," Channel allocation in mobile wireless network", thesis from Pontifical Catholic University of Parana, july 2018.

13. Carlos García-Martínez, Francisco J. RodriguezManuel Lozano, "Genetic Algorithms", Book "Handbook of Heuristics", August 2018, pp 431-464.

14. Koumousis V, Katsaras C (2006) A saw-tooth genetic algorithm combining the effects of variable population size and reinitialization to enhance performance. IEEE Trans Evol Comput, pp.19-28.

15. Holland, J. H. [1975]. "Adaptation in Natural and Artificial Systems," University of Michigan Press, Ann Arbor.

16. Matheus F. Torquato, Marcelo A. C. Fernandes, "High-Performance Parallel Implementation of Genetic Algorithm on FPGA", Distributed, Parallel, and Cluster Computing journal, juin 2018.

17. Usama Mehboob, Junaid Qadir, Salman Ali, Athanasios Vasilakos "Genetic algorithms in wireless networking: techniques, applications, and issues", Soft Computing volume 20, pp. 2467-2501, 2016.

18. Diaz-Gomez, P.A.; Hougen, D.F, "Initial population for genetic algorithms: A metric approach", GEM journal, 2007, pp. 43-49.

19. Ahmad Hassanat, Khalid Almohammadi, Esra'a Alkafaween, Eman Abunawas, Awni Hammouri, V. B. Surya Prasath,"Choosing Mutation and Crossover Ratios for Genetic Algorithms-A Review with a New Dynamic Approach", information journal, Volume 10 Issue 12, 2019.

20. Özgür Yeniay, " Penalty Function Methods for Constrained Optimization with Genetic Algorithms", MCA journal, Volume 10 Issue 1, 2005, pp. 45-56.

21. Michalewicz, Z and Attia,N.(1994) 'Evolutionary Optimization of constrained Problems,' Proccedings of the 3rd annual conference on evolutionary Programming, word scientific .
22. Aouam, T and Boulmalf,M, "A QoS Based Planning for IEEE802.11g Networks", Int. J. of Autonomous and Adaptive Communications Systems, Volume 2, Issue 2,2009.

\section{AUTHORS PROFILE}

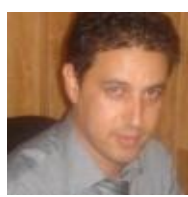

Hamid Barkouk, He obtained Master Degree in Computer Sciences from Faculty of Sciences,University of Abdelmalek Essaâdiin 2015, he is currently a PhD Student in LIST (Laboratoire d'Informatique Systemes et Telecommunications), Department of Computer Sciences. Faculty of Sciences and Technologies, Tangier, Morocco at the University of Abdelmalek Essaadi. His research interests include wireless sensor networks, wireless networking and communication. He is an Author/Co-Authors of several Articles and Chapters, published in The International Journals and in the conference proceedings as well as Chapters of books, in Computer Sciences.

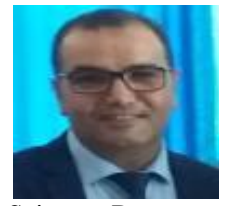

Dr. El Mokhtar EN-NAIMI, is a Professor in the University of Abdelmalek Essaâdi, Faculty of Sciences and Technologies of Tangier, Department of Computer Sciences, since 2000 (Temporary: from 2000 to 2003 and Professor Permanent: since 2003/2004 until Now). He is a Head of Computer Sciences Department, since October 2016 until now. He was responsible for a Bachelor of Science and Technology, BST Computer Engineering ("Licence LST-GI"), from January 2012 to October 2016. He is also a founding member of the Laboratory LIST (Laboratoire d'Informatique, Systèmes et Télécommunications), the University of Abdelmalek Essaâdi, FST of Tangier, Morocco. He is also an Expert Evaluator with the ANEAQ, since the academic year 2016/2017 until now, that an Expert of the Private Establishments belonging to the territory of the UAE and also an Expert of the Initial or Fundamental Formations and Formations Continuous at the Ministry of Higher Education, Scientific Research and Executive Training and also at the UAE University and the FST Tangier since 2012/2013 until Now. He is an Author/Co-Authors of several Articles, published in The International Journals in Computer Sciences, in particular, in Multi-Agent Systems (MAS), Cases Based Reasoning (CBR), Artificial Intelligent (AI), eLearning, MOOC, Big DATA, Data-mining, Wireless Sensor Network, VANet, MANet, Smart City, ..., etc. He is also Director of several Doctoral Theses in Computer Sciences. In addition, he is an associate member of the ISCN - Institute of Complex Systems in Normandy, the University of the Havre, France, since 2009 until Now.

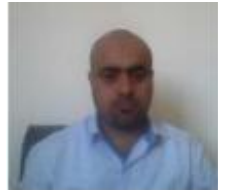

Aziz Mahboub, is a Professor in the University of Abdelmalek Essaâdi, Faculty of Sciences and Technologies of Tangier, Department of Computer Sciences, since September 2019 until Now. He is a member ofthe Laboratory LIST (Laboratoire d'Informatique, Systèmes et Télécommunications), the University of Abdelmalek Essaâdi, FST of Tangier, Morocco. He obtained Master Degree in Computer Sciences from Faculty of Sciences, UniversityofAbdelmalekEssaâdiin2008. He obtained His Doctorate $(\mathrm{PhD})$ in Computer Sciences from Faculty of Sciences and Technologies of Tangier, Department of Computer Sciences University of Abdelmalek Essaâdi in April 2019. His researches are in fields of Wireless Sensor Network, Internet of Things, wireless communications and mobile computing. He has served as invited reviewer. He has published research papers in IJECE Journal, JATIT Journal, conference proceedings as well as chapters of books, etc.

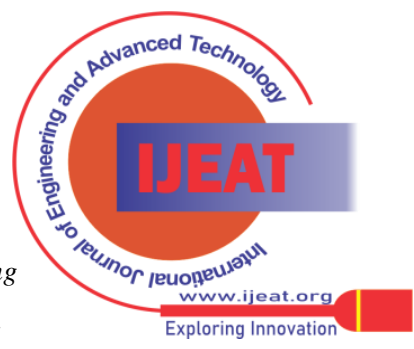

